\title{
EDTA Clearance
}

National Cancer Institute

\section{Source}

National Cancer Institute. EDTA Clearance. NCI Thesaurus. Code C100440.

A measurement of the volume of serum or plasma that would be cleared of

Ethylenediamine tetraacetic acid (EDTA) through its excretion for a specified unit of time. 